\title{
Examining Physical Activity and Play Behavior Preferences between First Graders and Last Graders in Primary School Children in Tehran
}

\author{
Noura Marouf ${ }^{1,2}$, Adi Irfan Che-Ani ${ }^{1} \&$ Norngainy Mohd Tawil ${ }^{3}$ \\ ${ }^{1}$ Department of Architecture, Faculty of Engineering and Built Environment, Universiti Kebangsaan Malaysia \\ (UKM), Bangi, Selangor, Malaysia \\ ${ }^{2}$ Islamic Azad Uuniversity, Gorgan Branch, Iran \\ ${ }^{3}$ Deputy Director for Entrepreneurship and SMEs Development, Universiti Kebangsaan Malaysia (UKM), bangi, \\ selangor, Malaysia
}

Correspondence: Noura Marouf, 329A, TKT 2, Jalan Tenaga 20, Taman Tenaga, Kajang, Selangor, 43000, Malaysia. Tel: 60-10-897-8906. E-mail: noura.marouf@gmail.com

Received: December 28, 2014 Accepted: March 12, 2015 Online Published: December 21, 2015

doi:10.5539/ass.v12n1p17

URL: http://dx.doi.org/10.5539/ass.v12n1p17

\begin{abstract}
School grounds are critical places because they are some of the few play areas available for children to develop and transfer peer culture. Moreover, school playtime, which is often called "recess", offers children daily opportunities for physical activity in the outdoor environment. During school years, age has always been presented in the studies on children as a fundamental component of their development. Children of different ages are interested in different play styles and have various play priorities. However, few studies have compared play patterns in children within age groups. This study explores play behaviors during recess in elementary school children overall, and secondly examines the differences in the play behavior of children, considering first graders who enter elementary school and the last graders. This study uses quantitative design and naturalistic observational approaches. An ethnogram recorded the observations of the play activities preferences of the children. The results of this study showed that girls spend the majority of their recess talking and socializing with peers generally. Older children, particularly those in grades fifth and sixth, spend more time socializing than other age groups. Children in the first grade spent much time in active free play, such as chasing and running, during recess and tend use their playtime as an opportunity to perform a physical activity; therefore the significance of combining recess and provisions for physical activity to reach health goals becomes clearer. These findings are interesting considerations for further research; such information could help to develop appropriate interventions to improve the recess.
\end{abstract}

Keywords: age influences on play activities, school recess, play preferences

\section{Introduction}

Play is a significant factor for social, emotional, physical, and cognitive skills development in children (Jenvey \& Jenvey, 2002). It is described as the behavior and different activities of children during their free time (Pellegrini, 2009). In general, play is naturally motivated by oneself, chosen freely, as well as flexible and enjoyable (Armitage, 2001; Pellegrini \& Smith, 1998; Titman \& McGill, 1992). It represents a significant part of the opportunities for physical activity in toddlers and school children (Pellegrini \& Smith, 1998; Rippe, Weissberg, \& Seefeldt, 1993).

In this regard, school grounds become significant sites which are critical places; because they are some of the few play areas available for children to develop and transfer peer culture (Factor, 2004). Moreover, school playtime, which is often called "recess", offers children daily opportunities for physical activity in the outdoor environment. Despite certain limitations, recess is the only time for them to play informally with other children during the school day (Thomson, 2004). Recently, Ramstetter et al. (2010) considered the play time of children as their personal time when they gain physical, mental, and social benefits thoroughly.

During recess, the behavior of a child, regarding to his interaction to physical and social environment, is counted as a result of the individual's attributes (Armitage, 2001; Pellegrini \& Smith, 1993). Previous studies have shown a difference between genders in both their physical activity and play behavior, which suggests that children use 
play time to be involved in various types of behaviors. In this regard, children's play choices could be influenced by their gender (Benjamin, 1932; Bjorklund \& Pellegrini, 2000; Caldera, Huston, \& O’Brien, 1989; Pellegrini \& Smith, 1993). A portion of the research on school grounds demonstrated that, in this context, boys and girls have extremely different play choices and preferences (Blatchford, Baines, \& Pellegrini, 2003; Pellegrini, 2004).

For instance, boys often tend to be involved in higher physical activity level and more vigorous activities (Benenson, 1993; Parrish, Iverson, Russell, \& Yeatman, 2009; Willenberg et al., 2010; Zask, van Beurden, Barnett, Brooks, \& Dietrich, 2001); compared with boys, girls mostly engage in socializing (Peter Blatchford, Baines, \& Pellegrini, 2003b). Rough-and-tumble play, as well as ball games, is the typical play choices of boys (Peter Blatchford et al., 2003b), whereas girls are more engaged in sedentary games, jump skipping, and verbal games. Similarly, Jarrett et al. investigated the play preferences of students in urban elementary schools during outdoor recess; girls preferred to play with equipment and boys played games (Jarrett, Farokhi, Young, \& Davies, 2001).

Overall, previous research on play choice and gender theory showed that boys and girls like to spend time with their peers, even if the aspects of the socialization vary according to age and gender. Boys seem to prefer intense, high-performance, competitive, and rough-and-tumble types of play (Maccoby, 2000, 2002; Pellegrini, 2004). Conversely, girls have a tendency to be more intimate and more involved in sedentary activities such as sitting and talking, which are based on social interaction and relationship-based support (Maccoby, 2000; Pellegrini, 2004). Some play activities are not specifically gendered, such as chasing, catching and seeking, racing (Peter Blatchford et al., 2003b, p. 491), counting-out rhyming (Ackerley, 2003), playing water games (Ferré, Guitart, \& Ferret, 2006), playing tag, building a hut, cycling, and roller skating (Karsten, 2003, p. 469).

Another well-documented variable that influences play choice is age (Benjamin, 1932). While children gain new motor and cognitive abilities, they absorb new and complex ways to play, and these new skills in selecting more complex play are exhibited over time. Developmental studies have shown that younger children tend to engage in chasing, whereas older children usually prefer more formal play such as sportive games. In addition, these studies suggest that the preference for rough-and-tumble play, as well as pretend and social play, changes with age (Scarlett, 2005).

For example, Blatchford (1996) suggested a considerable difference between the activities of primary and secondary level children during recess. Comparing 16-year-old with 11-year-old children, the researcher found the most important change to be their loss of interest in all other games except football; football was played by only $26 \%$ of the students, and other ball games were forgotten among 16-year-olds. In this age group, talking to friends, hanging around, and being social with peers were the most popular activities (72\%). Similarly, another study on the development of the playground games between 8-year-olds and 9-year-olds starting junior schools showed a progressive decrease in the range of games and the development of a few dominant ones during their first year (Peter Blatchford \& Sumpner, 1998). Study of Pellegrini (1993) on preadolescents examined the change in the preferences of boys and girls regarding their intensive outdoor activities when they transferred to middle school. Younger children were found to prefer playing outdoors for a longer time compared with older children and boys tended to stay outdoors to play longer than girls. Young boys are also originally interested in rough-and-tumble play, probably to assert their dominance and determine their social status among peers.

Therefore, age has always been presented in the studies on children as a fundamental component of their development. Although play among larger multi-age groups is undoubtedly a vital means of informal learning, it is not investigated sufficiently despite its usual occurrence in playground communities, including school grounds for different age groups. In fact, children of different ages are interested in different play styles and have various play priorities. However, few studies have compared play patterns in children within age groups.

Every play space should be considered to have its own lifetime. It has its specific structure and history which children mostly make in their terms (Thomson, 2004). In this regard, understanding the play behavior of children through the same environments becomes important (Pellegrini \& Bohn, 2005; Ridgers, Stratton, Fairclough, \& Twisk, 2007). These findings could be beneficial for school playtime in terms of developing interventions that not only increase the physical activities of children but also improve their overall health by considering developmental factors on a daily basis (Ramstetter, Murray, \& Garner, 2010).

Therefore, this study explores the differences and indicates the changes in the physical activity and play behavior of first-grade children, who recently entered elementary school, and the last-grade students, who will leave for middle school in subsequent years, during recess in the school grounds. 


\section{Method}

\subsection{Design and Procedure}

This study uses quantitative design and naturalistic observational approaches. An ethogram recorded the observations of the play activities preferences of the children. Preparation of the ethogram occurred over a pilot period of two weeks. Study began in September 2013 and ended in October 2013. Observers recorded the play activities of children using an ethogram extracted from Jarrett et al. (2001). Their work included the following categories: chasing, playing with the equipment, talking in groups, rule games of children, symbolic play, and solitary behavior; similarly, these play types also were documented in previous research (Holmes, 2006). The frequencies of behavior and age group of the child or children demonstrating the behavior were noted during playtime.

Time sampling was used to record behaviors uniformly. Rather than recording observations at spontaneous and inconsistent times, time sampling records observations at fixed, regular intervals of time and notes the occurrences precisely at these moments (Pellegrini, 2004). For this project, a time-sampling period of five minutes was selected partly because of its use in other studies in the literature (Jarrett et al., 1998). For pilot trials, five minutes seemed sufficient to cover the entire playground. The playground was divided into two quadrants, which are rectangular spaces in front of the two parish buildings. These divisions facilitated the ease of recording observations.

Data were gathered during only recess when children were able to access the school grounds. Observers went to the school grounds before the first recess and asked for information about the recess schedule. Prior to playtime, an observer located himself in a proper place in the school grounds where he would be able to observe the entire area. After children came to the school grounds alone or with their peers and started to play, recording the observations started. All the activities of the children were documented in right-to-left and back-to-front directions.

\subsection{Setting}

A public elementary schools in Tehran were selected to observe the children's behavior in playtime. The school has one playground, which consists of a tarmac surface area with a fence inside and two fixed sportive equipment that are available to children during playtime. The school does not provide portable equipment to play with. The only equipment that children have is a ball, which some children use during recess. In total, school recess is approximately 50 minutes and is subdivided into three 15- to 20-minute periods. During recess, children are not allowed to stay in the classrooms.

\subsection{Participants}

Participants were included students of a public elementary school from District three in Tehran. The population of the school is 533 children, mostly from middle-class socioeconomic backgrounds. Grades statistics are presented in Table 1.

Table1. Statistics by grade of child

\begin{tabular}{ccccccc}
\hline \multicolumn{9}{c}{ Grades } & \multicolumn{2}{c}{ Total } \\
\hline 1 st & 2nd & 3rd & 4th & 5 th & 6th \\
\hline 90 & 88 & 85 & 92 & 83 & 95 & 533 \\
\hline
\end{tabular}

\section{Result}

\subsection{Play Preference in the School Grounds}

In this section, the playground behavior and activities of children are considered. The findings are in terms of total and age group frequencies over the entire research period. Figure 1 presents tallied frequencies of all play types across all grades and the general play preferences of children during recess in the school grounds. In fact, most of the children in this primary school are girls, who preferred less physically vigorous play such as socializing. The figure shows the typical recess activities for these girls. These activities account for nearly $75 \%$ of all the observed play activities. Observers consistently found girls sitting and talking or walking arm in arm across the playground. 


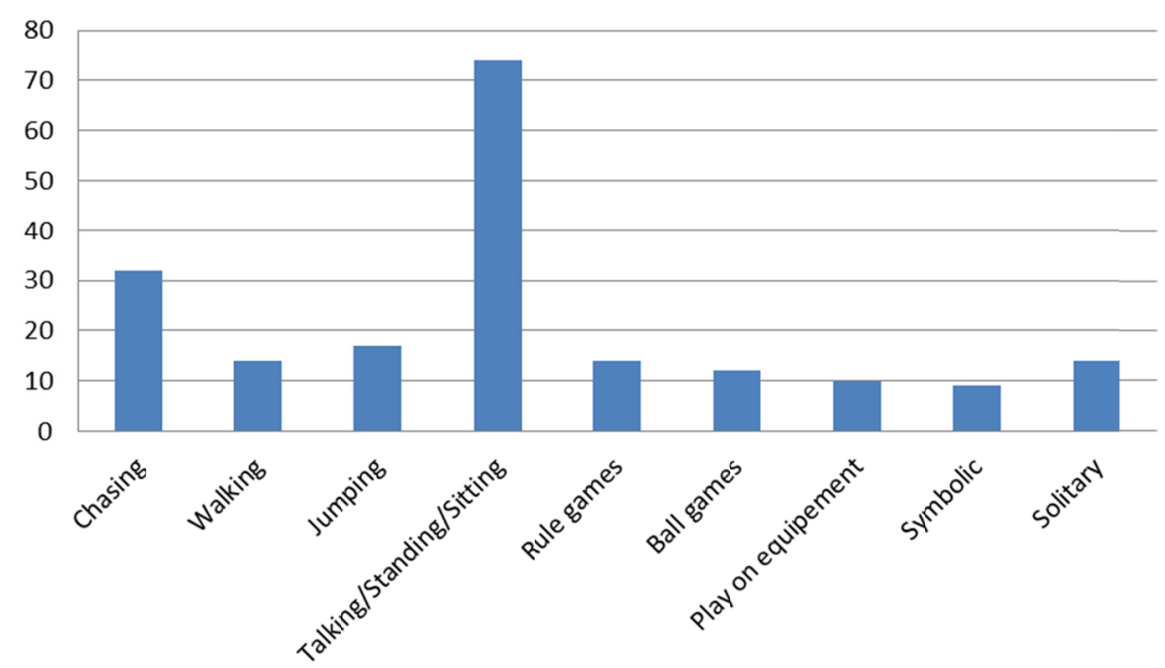

Figure 1. Children's play preferences for activities

\subsection{Play Preferences by Grade Group}

Figure 2 consists of tallied frequencies of all play types and presents the frequencies of the observed activities by grade groups. Primarily, younger girls engaged in more active free play such as running, chasing, and jumping. They accounted for $35 \%$ of all the different activities observed. Anecdotal observations also suggest that the quality of play of the children in kindergarten, first grade, and second grade differed from that of the older children. For example, younger children engage in chasing more often than older children. Chasing among younger children, however, seemed capricious and performed for its own sake. Chasing among older children appeared to be more purposeful or evolved from another play activity. Older children mostly prefer more organized and objective games such as ball games or some rule games.

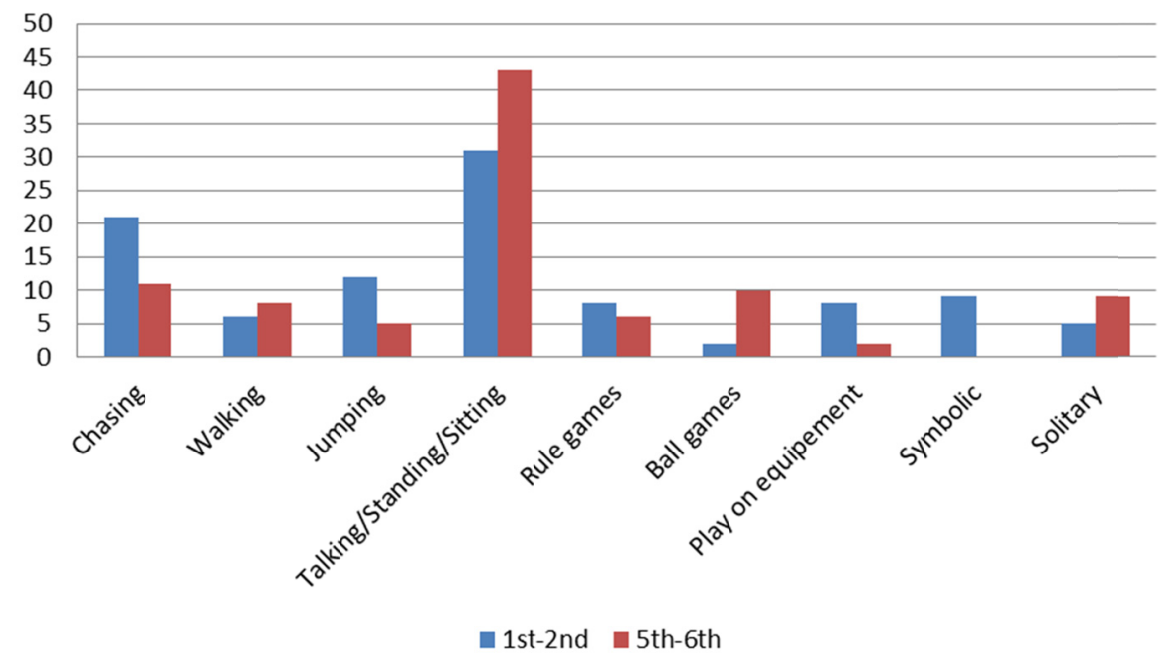

Figure 2. Children's play preferences for activities by age groups

Older children spent a significant amount of their time socializing and conversing with their peers, whereas younger children spent less time talking. This activity was preferred by children in grades 5 and 6 , who accounted for more than $40 \%$ of all students.

These elementary-school children selected solitary play infrequently compared to social and active play. Older children engaged in more solitary play than younger ones did. They often sat on available benches or walked throughout the recess period.

Given the lack of play equipment in this playground, children often congregated by the few elements existing in the playground, including the fence and two items of sportive equipment, which were popular play areas. At some point, all children talked while they leaned on or were near the fence. The younger children actually stood 
by the fence to rest in between chases, often leaning on it. Older children stood by the fence and conversed. Furthermore, younger children tended to use any flat stage in the playground as an area to gather and do symbolic play; they also used the sportive equipment mostly in pretend play.

\section{Discussion}

This study examines the differences in the play behavior of children during recess, considering first graders who enter elementary school and the last graders. The results of this study agree with those of earlier studies stating that girls spend the majority of their recess talking and socializing with peers (Peter Blatchford et al., 2003b; Renold, 1997; Swain, 2000). They mostly tend to be engaged in playground games (e.g., rule games and verbal games), sedentary activities, and loco-motor behavior (Ridgers et al., 2007; Stratton \& Mullan, 2005). Older children spent more time socializing than other age groups. In addition, the school grounds is socially structured and established obviously by children who have reached the latter years of primary school (Peter Blatchford \& Sumpner, 1998), as they have stayed with the same classmates and friends over a longer period of time. In this regard, researchers need to increase their knowledge in designing recess interventions.

Younger children spent much time in active free play, such as chasing and running, during recess; this type of play is more than just a recreational activity; the child is developing motor and coordination skills and testing their physical strength, while learning about their relationship with the physical environment (Tan, 1978; Stine, 1997). This observation shows that younger children use their playtime as an opportunity to perform a physical activity, and therefore the significance of combining recess and provisions for physical activity to reach health goals becomes clearer (Ridgers et al., 2007). This study also supports the findings of Jarrett et al. (2001) that younger children spend more time chasing than older children. Blatchford (1998b) considered that such games may appear childish or boring in the view of children over time, as they eagerly play more complex games such as rule or ball games, instead of basic ones (Pellegrini, Kato, Blatchford, \& Baines, 2002).

Solitary play seemed minimal compared with social play, which would suggest that children enjoyed recess and sought out play partners to join them in their play activities. Older children accounted for most of the solitary play, and only a few children notably accounted for the frequency of solitary play. Jarrett et al. (2001) reported similar findings in their work with urban children from public elementary schools.

The preceding review of the changing goals and behaviour of children as they pass through the phase of childhood has helped to highlight some of the activities and encounters that take on increased significance at various points during this period. It has been established that children are inherently motivated to develop, and their interests revolve around certain patterns of environmental interactions that are compatible with their current developmental goals.

\section{Conclusions}

Recess in school grounds provides opportunities for children to be involved in free play on a daily basis, in an environment that is safe and approximately unstructured. Overall, as previous research indicates, girls tend to be engaged in sedentary play behavior, and loco-motor activities. Some changes in the play behavior and activity levels of children were indicated during their transition from their first to their last school years. The decline occurred when students who participated in physically active games, such as chasing and running during the first grade, engaged in more sedentary activities, such as sitting and talking. Decreasing or omitting play time from the school-day schedule because of study priorities or behavioral problems could negatively affect the play choices, physical activity levels, and social behavioral development of children. These findings show that recess is an opportunity for children to be involved in and develop their social behaviors, and decreasing or omitting playtime may affect both the physical and social health of children.

The physical, social and cognitive advances that result from these activities further impact their environmental behaviour. It is therefore clear that both their motivations and interactions change as they progress through the sub-stages of middle childhood. The changing nature of a child's engagement with their physical and social environments over the course of childhood demonstrated that they value opportunities provided by their environments that are supportive of their current set of goals. Both their changing capabilities and motivations impact the affordances that they perceive or desire; children will attend to or seek out the functional opportunities in an environment that support their developmentally motivated intentions. These findings are interesting considerations for further research; such information could help to develop appropriate interventions to improve the recess.

\section{Limitations}

Several children from different grade levels played in the playground at the same time, so we observed several of 
them together and had no way of distinguishing students of different grade levels. The playground consisted of an asphalt surface with limited playground equipment. The setting clearly drove the behavior that occurred within it, and comparisons of different types of playgrounds would be interesting to examine in future studies.

\section{Acknowledgments}

The authors would like to express our heartfelt thanks to Universiti Kebangsaan Malaysia [Lestari Physical Development Research Group (LPhyD)] and the Evolutionary and Sustainable Urban Living Research Group (EvoSUL)] for supporting this research. Credit also goes to various organizations, which facilitated the successful completion of this research.

\section{References}

Ackerley, J. (2003). Gender differences in the folklore play of children in primary school playgrounds. Play and Folklore, 44, 2-15.

Armitage, M. (2001). The ins and outs of school playground play: children's use of "play places." Play Today in the Primary School Playground: Life, Learning and Creativity, 37-58.

Benenson, J. F. (1993). Greater preference among females than males for dyadic interaction in early childhood. Child Development, 64(2), 544-555. http://dx.doi.org/10.2307/1131268

Benjamin, H. (1932). Age and sex differences in the toy-preferences of young children. The Pedagogical Seminary and Journal of Genetic Psychology, 41(2), 417-429. http://dx.doi.org/10.1080/08856559.1932. 10533105

Bjorklund, D. F., \& Pellegrini, a D. (2000). Child development and evolutionary psychology. Child Development, 71(6), 1687-1708. http://dx.doi.org/10.1111/1467-8624.00258

Blatchford, P. (1994). Research on children's school playground behaviour in the United Kingdom. Breaktime and the School: Understanding and Changing Playground Behaviour, 15.

Blatchford, P., \& Sumpner, C. (1996). Changes to breaktime in primary and secondary schools. Final Report to Nuffield Foundation.

Blatchford, P. (1998). Social Life in the School: Pupils' Experience of Breaktime and Recess from 7 to 16 Years. London: Falmer Press.

Blatchford, P., Baines, E., \& Pellegrini, A. (2003). The social context of school playground games: Sex and ethnic differences, and changes over time after entry to junior school. British Journal of Developmental Psychology, 21(4), 481-505. http://dx.doi.org/10.1348/026151003322535183

Caldera, Y. M., Huston, A. C., \& O'Brien, M. (1989). Social interactions and play patterns of parents and toddlers with feminine, masculine, and neutral toys. Child Development, 70-76. http://dx.doi.org/10.2307/ 1131072

Factor, J. (2004). Tree Stumps, Manhole Covers and Rubbish Tins The Invisible Play-Lines of a Primary School Playground. Childhood, 11(2), 142-154. http://dx.doi.org/10.1177/0907568204043049

Ferré, M. B., Guitart, A. O., \& Ferret, M. P. (2006). Children and playgrounds in Mediterranean cities. Children's Geographies, 4(2), 173-183. http://dx.doi.org/10.1080/14733280600806999

Holmes, R. M. (2006). The Outdoor Recess Activities of Children at an Urban School Longitudinal and Intraperiod Patterns, 4(3), 327-351.

Jarrett, O. S., Maxwell, D. M., Dickerson, C., Hoge, P., Davies, G., \& Yetley, A. (1998). Impact of recess on classroom behavior: group effects and individual differences. The Journal of Educational Research, 92(2), 121-126. http://dx.doi.org/10.1080/00220679809597584

Jarrett, O. S., Farokhi, B., Young, C., \& Davies, G. (2001). Boys and girls at play: Recess at a southern urban elementary school. Play and Culture Studies, 3, 147-172.

Jenvey, V. B., \& Jenvey, H. L. (2002). Criteria used to categorize children's play: Preliminary findings. Social Behavior and Personality: An International Journal, 30(8), 733-740. http://dx.doi.org/10.2224/sbp.2002.30. 8.733

Karsten, L. (2003). Children's Use of Public Space: The Gendered World of the Playground. Childhood, 10(4), 457-473. http://dx.doi.org/10.1177/0907568203104005

Maccoby, E. E. (2000). Perspectives on gender development. International Journal of Behavioral Development, 


\section{4(4), 398-406. http://dx.doi.org/10.1080/016502500750037946}

Maccoby, E. E. (2002). Gender and group process: A developmental perspective. Current Directions in Psychological Science, 11(2), 54-58. http://dx.doi.org/10.1111/1467-8721.00167

Parrish, A.-M., Iverson, D., Russell, K., \& Yeatman, H. (2009). Observing children's playground activity levels at 13 Illawarra primary schools using CAST2.

Pellegrini, a. D., \& Smith, P. K. (1993). School Recess: Implications for Education and Development. Review of Educational Research, 63(1), 51-67. http://dx.doi.org/10.3102/00346543063001051

Pellegrini, A. D., \& Smith, P. K. (1998). Physical activity play: The nature and function of a neglected aspect of play. Child Development, 69(3), 577-598. http://dx.doi.org/10.1111/j.1467-8624.1998.tb06226.x

Pellegrini, a. D., Kato, K., Blatchford, P., \& Baines, E. (2002). A Short-term Longitudinal Study of Children's Playground Games Across the First Year of School: Implications for Social Competence and Adjustment to School. A. Educational Research J., 39(4), 991-1015. http://dx.doi.org/10.3102/00028312039004991

Pellegrini, A. D. (2004). Sexual segregation in childhood: A review of evidence for two hypotheses. Animal Behaviour, 68(3), 435-443. http://dx.doi.org/10.1016/j.anbehav.2003.07.023

Pellegrini, A. D., \& Bohn, C. M. (2005). Comment The Role of Recess in Children's Cognitive Performance and School Adjustment, (February), 13-19.

Pellegrini, A. D. (2009). Research and policy on children's play. Child Development Perspectives, 3(2), 131-136. http://dx.doi.org/10.1111/j.1750-8606.2009.00092.x

Ramstetter, C. L., Murray, R., \& Garner, A. S. (2010). The crucial role of recess in schools. The Journal of School Health, 80(11), 517-26. http://dx.doi.org/10.1111/j.1746-1561.2010.00537.x

Renold, E. (1997). All They've Got on Their Brains is Football. Sport, Masculinity and the Gendered Practices of Playground Relations. Sport, Education \& Society, 2(1), 5-23. http://dx.doi.org/10.1080/13573329700201 01

Ridgers, N. D., Stratton, G., Fairclough, S. J., \& Twisk, J. W. R. (2007). Children 's physical activity levels during school recess : a quasi-experimental intervention study, 9, 1-9.

Rippe, J. M., Weissberg, R. P., \& Seefeldt, V. (1993). The purpose of play: a framework for improving childhood health and psychological and physical development. Med Exerc Nutr Health, 2, 225-231.

Scarlett, W. G. (2005). Children's play. Sage.

Stratton, G., \& Mullan, E. (2005). The effect of multicolor playground markings on children's physical activity level during recess. Preventive Medicine, 41(5), 828-833. http://dx.doi.org/10.1016/j.ypmed.2005.07.009

Swain, J. (2000). “The Money”s Good, The Fame's Good, The Girls are Good: The role of playground football in the construction of young boys' masculinity in a junior school. British Journal of Sociology of Education, 21(1), 95-109. http://dx.doi.org/10.1080/01425690095180

Thomson, S. (2004). Just another classroom? Observations of primary school playgrounds. Sites of Sport: Space, Place, Experience. London: Routledge, 73-84.

Titman, W., \& McGill, I. (1992). Play, playtime and playgrounds: key issues for teachers, supervisors and governors of primary schools. LTL/WWF UK.

Willenberg, L. J., Ashbolt, R., Holland, D., Gibbs, L., MacDougall, C., Garrard, J., ... Waters, E. (2010). Increasing school playground physical activity: a mixed methods study combining environmental measures and children's perspectives. Journal of Science and Medicine in Sport, 13(2), 210-216. http://dx.doi.org/10. 1016/j.jsams.2009.02.011

Zask, a, van Beurden, E., Barnett, L., Brooks, L. O., \& Dietrich, U. C. (2001). Active school playgrounds-myth or reality? Results of the "move it groove it" project. Preventive Medicine, 33(5), 402-8. http://dx.doi.org/10.1006/pmed.2001.0905

\section{Copyrights}

Copyright for this article is retained by the author(s), with first publication rights granted to the journal.

This is an open-access article distributed under the terms and conditions of the Creative Commons Attribution license (http://creativecommons.org/licenses/by/3.0/). 